\title{
The vocational education setting for health promotion: a survey of students' health risk behaviours and preferences for help
}

\author{
Billie Bonevski ${ }^{\mathrm{A}, \mathrm{D}}$, Ashleigh Guillaumier $^{\mathrm{A}}$, Christine Paul $^{\mathrm{B}}$ and Raoul Walsh ${ }^{\mathrm{C}}$ \\ ASchool of Medicine and Public Health, University of Newcastle, Level 5, McAuley Centre, The Calvary-Mater Hospital, \\ Cnr Edith Street and Platt Street, Waratah, NSW 2298, Australia. \\ BHealth Behaviour Research Group, School of Medicine and Public Health, University of Newcastle, Callaghan, NSW 2308, \\ Australia. \\ CSchool of Medicine and Public Health, University of Newcastle, Callaghan, NSW 2308, Australia. \\ ${ }^{D}$ Corresponding author. Email: billie.bonevski@newcastle.edu.au
}

\begin{abstract}
Background: Adolescence and young adulthood is a time of risky health behaviour initiation and experimentation. Smoking, risky drinking, poor nutrition and physical activity, and a lack of sun protection behaviour, often become established in early adulthood. Levels of health risk behaviours occurring amongst tertiary education and training students and their preferences for types of oncampus health promotion programs were examined.

Method: A cross-sectional pen-and-paper classroom survey was conducted at one Sydney-based TAFE New South Wales Institute campus in May 2010. The survey assessed demographics, smoking, alcohol use, sun protection, nutrition, physical activity and health promotion program preferences.

Results: Two hundred and twenty-four students participated (97\% consent); the majority were aged 16-24 years (59\%) and female (51\%). Current smoking (35\%), risky drinking (49\%) and inadequate physical activity (88\%) rates were high. Adequate vegetable intake (3.6\%) and sun protection behaviours (5.4\%) were low and 33\% of students were overweight or obese. Popular health promotion programs included food and activity subsidies, practical skills classes and social outings.

Conclusion: Participation in health risk behaviours among this sample was high. The setting of tertiary education and workplace training represents an opportunity for early intervention into risky health behaviours among young people.

So what? This study is the first to provide information on the prevalence of health risk behaviours and preferences for types of health promoting programs among students of an Australian community college. The results show that young adults regularly participate in multiple health risk behaviours, such as smoking, drinking, poor nutrition, physical activity and lack of sun protection.
\end{abstract}

Received 24 June 2013, accepted 25 November 2013, published online 19 December 2013

\section{Introduction}

During adolescence and early adulthood, engaging in health risk behaviours such as heavy alcohol drinking and tobacco smoking, increases. ${ }^{1-3}$ While these behaviours are often first tried and initiated in school-aged adolescents, ${ }^{4-6}$ there is evidence to suggest that these behaviours become established later in young adulthood., In Australia health risk behaviours amongst youth are high. Of 12-24-year-old Australians in 2007-08, 35\% were obese, 66\% did not meet physical activity guidelines, $5 \%$ ate the recommended daily amounts of fruit and vegetables, 35\% use sunscreen during peak ultraviolet (UV) times, 11\% were daily smokers and 12\% drank alcohol at risky or high risk levels for long-term harm. ${ }^{8}$ Health risk behaviours are higher amongst youth from lower socioeconomic backgrounds. ${ }^{8}$ Males and females had similar patterns of most health risk behaviours; however, males were twice as likely as females to be obese. Reaching young adults during the post-school phase may prevent experimentation progressing to established behaviour.

The tertiary education and training setting presents an opportunity for reaching adolescents and young adults who may be at risk of transitioning to established unhealthy risk behaviours. ${ }^{9-13}$ In particular, Technical and Further Education (TAFE) in Australia is a popular tertiary education option, with TAFE New South Wales (NSW) receiving 1.6 times the number of enrolments of universities in NSW in 2011. 14,15 TAFE also has large numbers of students from lower socioeconomic status backgrounds and those who are interested in formal trade or vocational training. ${ }^{16}$ 
Surprisingly little has been reported of the health risk behaviours of TAFE students. Three dated studies (1997 and 1999) examining the prevalence of smoking among students found rates as high as 47\%. ${ }^{17-19}$ However, smoking prevalence rates have diminished significantly in Australia in the last 20 years. Only one of these studies measured other health behaviours. ${ }^{18}$ Fisher et al. ${ }^{18}$ found that $41 \%$ of 236 TAFE students reported 'eating healthier food', 25\% reported 'watching less TV', 27\% reported 'exercising regularly', 22\% reported 'stopping or drinking less alcohol' and 17\% reported 'stopping or cutting down on smoking' in the last 12 months to improve their health. The results suggest low levels of 'healthy' behaviours. These data do not, however, provide prevalence of health risk behaviours amongst TAFE students. Other than smoking prevalence rates in 1997 and 1999, rates of other health risk behaviours remains unknown.

The current study sought to address the gap in current knowledge regarding the health risk behaviours of younger TAFE students and their preferences for types of health promoting strategies. The aim of this study was to measure the prevalence of six health risk behaviours amongst students attending a large TAFE NSW college. The behaviours of interest were (1) tobacco smoking, (2) risky alcohol drinking, (3) use of sun protection and tanning behaviour, (4) fruit and vegetable intake, (5) physical activity, and the health risk factor (6) overweight or obesity. Students were also asked about their preferences for type of on-site campus health programs.

\section{Methods}

\section{Setting}

Surveys were undertaken at one campus site from a Sydney-based TAFE NSW Institute in May 2010. The institute, which received 50239 student enrolments in 2010, comprises seven campuses specialising in different trades such as hospitality, electrical and auto mechanics.

\section{Student sample and recruitment}

The study was approved by the University of Newcastle Human Research Ethics Committee. A convenience sample of students was recruited during class time. Researchers attended a campus staff meeting with $\sim 10$ senior staff members and explained the study and eligibility criteria. Eligible classes were those with a high number of English-speaking students, on-campus classes and included a high proportion of younger students (16-24 years). One staff member at the meeting (a key contact) identified potentially eligible classes and consenting teachers nominated suitable days for conducting the survey. The key contact was mailed information letters about the project to distribute to participating class teachers $(n=17) 1$ week before survey administration to allow students sufficient time to consider the invitation to participate. Survey administration was conducted over a 2-day period. Researchers attended the nominated classes, gave a brief overview of the project, explaining the survey was anonymous and confidential, and that survey completion would be taken as consent. Paper surveys and envelopes were distributed to all students in the class who were interested. No identifying information was collected, and students were asked to return their surveys, completed or blank, into a collection box that was only available in class. Participating classes were in the subjects of: real estate, marketing, hospitality, tourism, community services, automotive mechanics, nursing, aged care and carpentry.

\section{Measures and definitions of health status}

The survey instrument was constructed with feedback from behavioural scientists in the areas of alcohol, physical activity and nutrition, and pilot testing was conducted with one class of students from another TAFE NSW Institute, to ensure brevity and acceptability. The health risk survey included the top five modifiable lifestyle health behaviours in Australia. ${ }^{20}$ Sun protection and tanning behaviour were also included because of the high prevalence of skin cancer in Australia. ${ }^{21}$ The following items were asked:

\section{Demographics}

Items assessed age and gender, income, country of birth, language spoken at home, living arrangements, TAFE attendance and years at TAFE.

\section{Smoking status}

Current smoking was assessed by asking 'Do you currently smoke tobacco', with response options 'Yes, daily/yes at least once per week/yes at least once per month/no, not at all'. 'Current smokers' were those reporting daily or occasional smoking. Current smokers were asked about the number of cigarettes smoked per day, their smoking identity and their smoking behaviour before attending TAFE. Non-smokers were asked whether they would smoke if their friends offered them a cigarette.

\section{Alcohol consumption}

Alcohol consumption and related harm was assessed using the 10-item AUDIT scale 22,23 which has been evaluated in a college sample. ${ }^{24}$ The third AUDIT question was modified, reducing the criteria for the number of standard drinks consumed on one occasion from six to four to reflect changes in the Australian National Health and Medical Research Council guidelines for alcohol consumption. ${ }^{25}$ A cut-off score of $\geq 8$ was used to identify risky or hazardous drinking, and scores of $\geq 13$ for women or $\geq 15$ for men were used to indicate likely alcohol dependence. ${ }^{26}$ Current National Health and Medical Research Council guidelines define 'binge' drinking as the consumption of more than four standard alcoholic drinks in a single occasion of drinking. ${ }^{25}$

\section{Fruit and vegetable consumption}

Two items were used to assess daily (1) fruit serves and (2) vegetables serves. Both items have been validated for population assessment of fruit and vegetable consumption and used in several national health and nutrition surveys. ${ }^{27,28}$ A serve of vegetables was described as ' $1 / 2$ cup of cooked vegetables like carrot or peas, or 1 cup of salad' and serve of fruit as " 1 medium piece of fruit like an apple, 2 small pieces like apricots or 1 cup of chopped or canned fruit'. Inadequate 
consumption was defined as consuming $<2$ serves of fruit or $<5$ serves of vegetables per day. ${ }^{29}$

\section{Physical activity}

Validated questions from the Active Australia survey assessed total time spent (1) engaging in moderate physical activity and (2) engaging in vigorous physical activity in the last 7 days. ${ }^{30}$ The number of sessions of each activity was also assessed. National physical activity guidelines recommend at least 30 min of moderate intensity physical activity on most days of the week. ${ }^{31}$ Inadequate activity was defined as $<150$ min of physical activity in the previous week or less than five sessions of physical activity per week.

\section{Obesity and overweight}

Height and weight were used to calculate the standard Body Mass Index (BMI) definitions of healthy weight ranges.

\section{Sun protection use and sun tanning behaviour}

Seven items adapted from the National Skin Survey ${ }^{32}$ assessed sun protection use and sun tanning behaviour. To assess suntan behaviour, participants were asked 'Did you make any attempt to get a suntan during last summer?' Participants were asked to report their usual sun protection practices (from a pre-defined list) when outside for more than 15 min on a summer day, answering on a 5-point Likert scale ('never' to 'always'). Sun protection behaviour was classified as routine if participants answered 'usually' or 'always', but was defined as infrequent if participants answered 'never', 'rarely', or 'sometimes. 33 Inadequate sun protection was defined as less than five sun protection behaviours practised routinely.

\section{Preferences for help}

All respondents were asked to view a pre-defined list of potential health promotion programs and select the options they thought should be made available to TAFE students to help them be healthier. Smokers were also asked to nominate their preferences for quit support from a pre-defined list of common options.

\section{Analysis}

Demographics, health risk behaviours and health program preferences are reported using proportions and 95\% confidence intervals. Gender and age ( $\leq 24$ years versus $\geq 25$ years) comparisons on health risk behaviours were made using simple chi-square analyses. All analyses were conducted using SAS statistical software version $9.2 .^{34}$

\section{Results}

\section{Sample}

Of the 231 students approached to participate in the classroom survey, 224 consented (97\% consent rate). Table 1 shows the background demographics of the sample.

\section{Individual health risk behaviours}

Table 2 presents the prevalence of health risk behaviours among the TAFE student sample, as well as gender and age comparisons. The majority of participants did not meet minimum requirements for adequate vegetable intake, physical activity and sun protection; half consumed inadequate servings of fruit; and one-third fell into the 'overweight' or 'obese' BMI categories. Although most participants were deemed unlikely to be alcohol dependent, about half the sample used alcohol in a risky way. A large proportion of participants reported to smoke. Chi-square analyses showed younger students ( $\leq 24$ years) were more likely to be risky drinkers and alcohol dependent, not eating enough fruit, neglecting sun-safe practices and intentionally tanning. Additionally, males were more likely to smoke, engage in risky drinking and fail to practice sun-safe behaviours, however females were more likely to be insufficiently physically active and to intentionally suntan (Table 2).

Among the sample, 22\% were daily smokers and 13\% smoked occasionally; Table 3 presents participant smoking characteristics. Non-smokers ( $n=142 ; 65 \%)$ reported that they would 'definitely not' (65\%), 'probably not' (23\%), 'probably yes' (9\%) or 'definitely yes' (3\%) smoke if a friend offered it to them.

\section{Multiple health risk behaviours}

Participation in multiple health risk behaviours was high. Out of a possible eight health risk behaviours (vegetable intake, fruit intake, physical activity, BMI, sun protection use, intentional tanning, smoking and alcohol use), 1.83\% reported two health risk behaviours, the majority (89\%) reported participating in three to six health risk behaviours, and $9.63 \%$ reported engaging in seven to eight health risk behaviours.

\section{Health programs at TAFE}

Participant preferences for strategies that would help them to be healthier or to quit smoking are presented in Tables 4 and 5 .

\section{Discussion}

This survey provides new data on the prevalence of health risk behaviours among TAFE students in Australia. Smoking, and risky drinking rates were higher than those reported in general national samples and levels of physical activity behaviour and vegetable intake were lower than those found in national surveys. ${ }^{8}$ Use of sun protection and rates of overweight and obesity were similar as those found in the general population surveys of young adults. ${ }^{8}$ Most of the sample (98\%) reported at least two of the health risk behaviours measured, and the majority of participants reported between three and six health risk behaviours, dramatically increasing their risk of morbidity and mortality. Younger TAFE students were more likely to engage in several health risk behaviours than those ages over 25 years. Participants reported interest in a range of health improvement strategies including subsidised gym memberships and availability of healthy food options for general health.

\section{Promoting health behaviour change at TAFE}

The study results highlight the need to address numerous health risk behaviours among the TAFE student population, particularly younger students who appear to be showing higher rates of some health 
Table 1. Demographic characteristics of the TAFE survey sample and where available, those of the entire TAFE institute $\mathrm{n} / \mathrm{a}$, not available

\begin{tabular}{|c|c|c|c|c|}
\hline \multirow[t]{2}{*}{ Characteristic } & \multicolumn{2}{|c|}{ Participating classes $(n=224)$} & \multicolumn{2}{|c|}{ TAFE institute $(n=49379)^{\mathrm{E}}$} \\
\hline & $n$ & $\%[95 \% \mathrm{Cl}]$ & $n$ & $\%$ \\
\hline \multicolumn{5}{|l|}{ Age (years) } \\
\hline$\leq 24$ & 132 & $58.93[52.44-65.42]$ & 22595 & 46 \\
\hline$\geq 25$ & 92 & $41.07[34.58-47.56]$ & 26784 & 55 \\
\hline \multicolumn{5}{|l|}{ Gender } \\
\hline Male & 109 & $48.66[42.06-55.26]$ & 24665 & 50 \\
\hline Female & 115 & $51.34[44.74-57.94]$ & 24714 & 50 \\
\hline \multicolumn{5}{|l|}{ Country of birth ${ }^{A}$} \\
\hline Australia & 145 & $67.13[60.82-73.44]$ & $\mathrm{n} / \mathrm{a}$ & $\mathrm{n} / \mathrm{a}$ \\
\hline Other ${ }^{\mathrm{D}}$ & 71 & 32.88 & & \\
\hline \multicolumn{5}{|c|}{ Main language spoken at home ${ }^{B}$} \\
\hline English & 169 & 80.09 [74.66-85.53] & 16411 & 33 \\
\hline Other ${ }^{\mathrm{D}}$ & 42 & 19.90 & & \\
\hline \multicolumn{5}{|l|}{ Living arrangement ${ }^{\mathrm{A}}$} \\
\hline With parent/guardian & 120 & 55.56 [48.89-62.03] & $\mathrm{n} / \mathrm{a}$ & $\mathrm{n} / \mathrm{a}$ \\
\hline No parents/guardian & 96 & $44.44[37.76-51.12]$ & & \\
\hline \multicolumn{5}{|l|}{ Personal weekly income ${ }^{A}$} \\
\hline$<\$ 300$ & 100 & 46.29 [39.77-52.95] & $\mathrm{n} / \mathrm{a}$ & $\mathrm{n} / \mathrm{a}$ \\
\hline$\geq \$ 300$ & 55 & $25.46[20.12-31.67]$ & & \\
\hline None & 61 & $28.24[22.19-34.29]$ & & \\
\hline \multicolumn{5}{|l|}{ TAFE attendance ${ }^{c}$} \\
\hline Full time ( $\geq 20 \mathrm{~h} /$ week) & 128 & 58.99 [52.39-65.58] & $\mathrm{n} / \mathrm{a}$ & $\mathrm{n} / \mathrm{a}$ \\
\hline Part time (<20 h/week) & 66 & $30.41[24.25-36.58]$ & & \\
\hline Other ${ }^{\mathrm{D}}$ & 23 & $10.60[7.17-15.40]$ & & \\
\hline \multicolumn{5}{|l|}{ Years studied at TAFE ${ }^{A}$} \\
\hline 1 year & 133 & $61.57[55.04-68.11]$ & $\mathrm{n} / \mathrm{a}$ & $\mathrm{n} / \mathrm{a}$ \\
\hline$\geq 2$ years & 83 & $38.43[32.20-45.06]$ & & \\
\hline
\end{tabular}

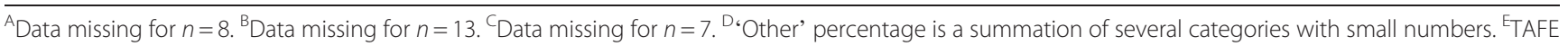
Institute statistics taken from the 'NSI at a glance - Performance Achievements' (http://www.nsi.tafensw.edu.au/About/NSI_at_a_glance.aspx)

risk behaviours than students aged over 25 years. Interventions addressing multiple health risk behaviours have been found to be effective in previous studies. ${ }^{35}$ It may be that the greatest benefits could be achieved by an approach that addresses multiple health risk behaviours; however, this should be evaluated in the TAFE setting. The study also presents some evidence to support the development of multiple health risk behaviour change programs that are tailored to student gender with males more likely to smoke and consume potential harmful amounts of alcohol and females more likely to intentionally suntan and not be physically active.

The most popular health promotion programs selected by respondents in this sample involved subsidies to physical activities and healthy foods, practical skills (cooking classes) and social outings (walking groups). These program choices represent practical solutions to aid positive decision making, to improve the uptake of healthy lifestyle behaviours, and to make health conscious behaviour more affordable. Previous research has shown that similar health programs such as the promotion of healthy food choices in a university food hall setting ${ }^{36}$ and the restriction of access to junk food in primary and secondary schooling settings ${ }^{37}$ are well accepted and effective in improving the health behaviours of the target groups. The most popular quit smoking strategies were own willpower, other, quitting with a friend and hypnosis, suggesting that there is a lack of understanding about the most effective, evidence-based strategies that support successful cessation among this population. This is a clear area for health promotion improvement.

Health behaviour change within a setting like TAFE would be best promoted with organisational support and concurrent policy development. Staff involvement and endorsement of health promotion programs is a key feature of effective policy implementation. This model has been used within other educational settings including schools. ${ }^{38,39}$ Given the results of the current study suggest student are open to the introduction of health programs, combined with previous research suggesting that TAFE staff are supportive of changes towards healthier campuses ${ }^{37}$ this approach should be trialled and evaluated within the TAFE setting.

\section{Limitations}

The main limitation of the study is its reliance on self-report, which may be introducing biases and underestimating prevalence of health risk behaviours. However, student self-report of health risk behaviours in a classroom setting have found to be reasonably accurate in environments where strong ethical safeguards are perceived to exist. ${ }^{40}$ Additionally, as this study was conducted with a convenience sample at one test site, the results of the research may have limited external validity and generalisability. 


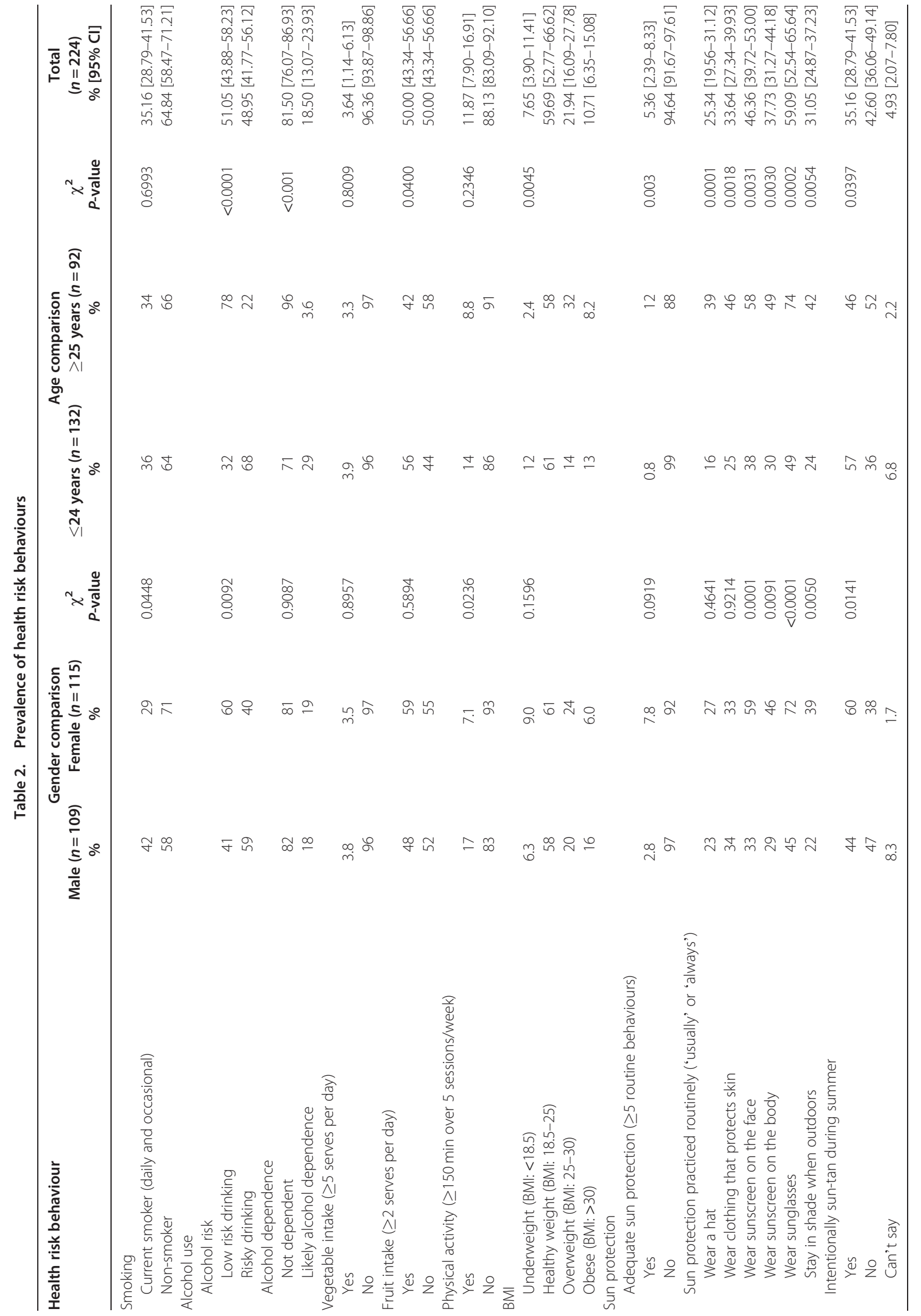


Table 3. Smoking characteristics of the TAFE survey sample (smokers only)

\begin{tabular}{lc}
\hline Characteristic & $\%[95 \% \mathrm{Cl}]$ \\
\hline Smoker identity & \\
Regular smoker & $45.68[34.60-56.76]$ \\
Social smoker & $23.46[14.03-32.88]$ \\
Occasional smoker & $14.81[6.91-22.72]$ \\
Pot smoker & $12.35[5.03-19.66]$ \\
Heavy smoker & $9.88[3.24-16.51]$ \\
Irregular smoker & $7.41[1.58-13.23]$ \\
Ex-smoker & $2.47[0.00-5.92]$ \\
Non-smoker & $2.47[0.00-5.92]$ \\
Cigarettes smoked per day & \\
1-10 & $64.10[53.22-74.99]$ \\
$11-30$ & $19.23[10.29-28.17]$ \\
31 or more & $2.56[0.00-6.15]$ \\
Only smoke cigars or pipes & $3.85[0.00-8.21]$ \\
Don't know & $10.26[3.37-17.14]$ \\
Daily smoker before TAFE & \\
Yes & $62.50[51.66-73.34]$ \\
No & $33.75[23.16-44.34]$ \\
Don't remember & $3.75[0.00-8.00]$ \\
\hline
\end{tabular}

Table 4. Preferences for health programs at TAFE

Participants could select more than one response. Percentages to do not add to $100 \%$

\begin{tabular}{lc}
\hline Program & $\%[95 \% \mathbf{C l}]$ \\
\hline Subsidised gym membership & $72.02[66.01-78.02]$ \\
Subsidised healthy food on campus & $41.74[35.15-48.34]$ \\
Healthy cooking classes & $25.23[19.42-31.04]$ \\
Walking groups & $24.31[18.57-30.05]$ \\
Seminars at TAFE about healthy eating and nutrition & $22.94[13.31-28.56]$ \\
Seminars at TAFE about weight management & $22.02[16.47-27.56]$ \\
Web-based 'healthy living' programs & $18.81[13.58-24.04]$ \\
Other & $16.51[11.55-21.48]$ \\
None of these & $6.88[3.49-10.27]$ \\
\hline
\end{tabular}

\section{Conclusions}

This study is the first to provide information on the prevalence of health risk behaviours and preferences for types of health promoting programs among students of an Australian community college. The results show that young adults regularly participate in multiple health risk behaviours, such as smoking, drinking, poor nutrition, physical activity and lack of sun protection. Additionally, students are open to a range of health promotion programs within the community college setting, particularly programs that would involve subsidies to physical activity and healthy food initiatives.

\section{Acknowledgements}

The study was conducted by the University of Newcastle and supported by a Strategic Research Partnership Grant from the NSW Cancer Council to the Newcastle Cancer Control Collaborative, with infrastructure support from the Hunter Medical Research Institute.
Table 5. Preferences for quit support (smokers only)

Participants could select more than one response. Percentages to do not add to $100 \%$

\begin{tabular}{lc}
\hline Support & $\%[95 \% \mathrm{Cl}]$ \\
\hline No help - use of own willpower & $44.44[33.39-55.50]$ \\
Quit smoking with a friend & $16.05[7.88-24.22]$ \\
Hypnosis & $16.05[7.88-24.22]$ \\
Vouchers for free or cheap nicotine patches or gum & $11.11[4.12-18.10]$ \\
Not allowing smoking at TAFE & $9.88[3.24-16.51]$ \\
Wouldn't recommend quitting & $6.25[0.83-11.67]$ \\
Not allowing smoking at worksites & $6.17[0.82-11.53]$ \\
Group quit program & $4.94[0.12-9.76]$ \\
SMS or texting-based programs & $4.94[0.12-9.76]$ \\
Acupuncture & $4.94[0.12-9.76]$ \\
Group programs at TAFE & $3.70[0.00-7.91]$ \\
Telephone support (e.g. Quitline) & $3.70[0.00-7.91]$ \\
A quit book or pamphlet & $2.47[0.00-5.925]$ \\
Movies/DVDs about quitting & $2.47[0.00-5.92]$ \\
Sessions with an on-site counselor or advisor & $2.47[0.00-5.92]$ \\
Computer or Web-based programs & $2.47[0.00-5.92]$ \\
Group programs somewhere else & 0 \\
None of these & $18.75[10.01-27.49]$ \\
\hline
\end{tabular}

The views expressed are not necessarily those of the Cancer Council. BB is supported by a Cancer Institute NSW Career Development Fellowship. AG is supported by an Australian Postgraduate Award. Our gratitude is extended to study participants and our collaborators at TAFE NSW, particularly Mr Malcolm Boyes. The assistance of Associate Professor Kypros Kypri and Associate Professor Erica James in developing the survey instrument is also gratefully acknowledged.

\section{References}

1. Australian Institute of Health and Welfare. Australia's health 2010. Canberra: AlHW2010. Report No.: Cat. no. AUS 122.

2. Grunbaum JA, Kann L, Kinchen SA, Williams B, Ross JG, Lowry R, et al. Youth Risk Behavior Surveillance — United States, 2001. J Sch Health 2002; 72(8): 313-28. doi:10.1111/j.1746-1561.2002.tb07917.x

3. Von Ah D, Ebert S, Ngamvitroj A, Parj N, Kang D. Predictors of health behaviours in college students. J Adv Nurs 2004; 48(5): 463-74. doi:10.1111/j.1365-2648. 2004.03229.x

4. Leatherdale ST, Burkhalter R. The substance use profile of Canadian youth: Exploring the prevalence of alcohol, drug and tobacco use by gender and grade. Addict Behav 2012; 37(3): 318-22. doi:10.1016/j.addbeh.2011.10.007

5. Warren CW, Kann L, Small ML, Santelli JS, Collins JL, Kolbe $\sqcup$. Age of initiating selected health-risk behaviors among high school students in the united states. J Adolesc Health 1997; 21(4): 225-31. doi:10.1016/S1054-139X(97)00112-2

6. Wechsler $\mathrm{H}$, Rigotti NA, Gledhill-Hoyt J, Lee $\mathrm{H}$. Increased levels of cigarette use among college students. JAMA 1998; 280(19): 1673-8. doi:10.1001/jama.280.19. 1673

7. Bernat $\mathrm{DH}$, Erickson DJ, Widome R, Perry $\mathrm{CL}$, Forster JL. Adolescent smoking trajectories: results from a population-based cohort study. J Adolesc Health 2008; 43(4): 334-40. doi:10.1016/j.jadohealth.2008.02.014

8. Australian Institute of Health and Welfare. Young Australians: their health and wellbeing 2011. Canberra: AlHW2011 Contract No.: Cat no. PHE 140.

9. Bush K, Kivlahan DR, McDonell MB, Fihn SD, Bradley KA. The audit alcohol consumption questions (audit-c): An effective brief screening test for problem drinking. Arch Intern Med 1998; 158(16): 1789-95. doi:10.1001/archinte.158.16.1789

10. Giskes K, Kunst AE, Benach J, Borrell C, Costa G, Dahl E, et al. Trends in smoking behaviour between 1985 and 2000 in nine European countries by education. J Epidemiol Community Health 2005; 59(5): 395-401. doi:10.1136/jech.2004.025684

11. James R. Socioeconomic background and higher education participation: An analysis of school students' aspirations and expectations. Canberra: Department of Education, Science and Training; 2002. 
12. Kypri K, Langley JD, Saunders JB, Cashell-Smith ML, Herbison P. Randomized controlled trial of web-based alcohol screening and brief intervention in primary care. Arch Intern Med 2008; 168(5): 530-6. doi:10.1001/archinternmed.2007.109

13. Kypri K, Saunders JB, Williams SM, McGee RO, Langley JD, Cashell-Smith ML, et al. Web-based screening and brief intervention for hazardous drinking: a double-blind randomized controlled trial. Addiction 2004; 99(11): 1410-7. doi:10.1111/j.13600443.2004.00847.x

14. NSW Department of Education and Communities. Annual report 2011. Sydney: 2012.

15. Department of Industry Innovation Science Research and Tertiary Education. 2011 Student Full Year. 2012. Available from: http://www.innovation.gov.au/ highereducation/HigherEducationStatistics/StatisticsPublications/Pages/2011Stu dentFullYear.aspx [Verified August 2013]

16. NSW Department of Education and Training. Annual report 2006. Sydney: DET; 2007.

17. Edwards D, Wakefield M, Roberts L, Owen N. Smoking behaviour, stage of change and preferences for cessation assistance among young people attending an institute of Technical and Further Education (TAFE). Health Promot J Austr 1997; 7: $18-21$.

18. Fisher KJ, Stanton WR, Lowe JB. Healthy behaviors, lifestyle, and reasons for quitting smoking among out-of-school youth. J Adolesc Health 1999; 25(4): 290-7. doi:10.1016/S1054-139X(98)00157-8

19. Stanton WR, Lowe JB, Fisher J, Gillespie AM, Rose JM. Beliefs about smoking cessation among out-of-school youth. Drug Alcohol Depend 1999; 54(3): 251-8. doi:10.1016/ S0376-8716(98)00160-4

20. Australian Institute of Health and Welfare. Australia's health 2008. Cat. no. AUS 99. Canberra: AlHW; 2008.

21. Australian Institute of Health and Welfare. Cancer in Australia: an overview, 2008. Canberra: 2009.

22. Bradley KA, DeBenetti AF, Volk RJ, Williams EC, Frank D, Kivlahan DR. AUDIT-C as a brief screen for alcohol misuse in primary care. Alcohol Clin Exp Res 2007; 31(7): 1208-17. doi:10.1111/j.1530-0277.2007.00403.x

23. Saunders JB, Aasland OG, Babor TF, De La Fuente JR, Grant M. Development of the Alcohol Use Disorders Identification Test (AUDIT): WHO collaborative project on early detection of persons with harmful alcohol consumption II. Addiction 1993; 88(6): 791-804. doi:10.1111/j.1360-0443.1993.tb02093.x

24. Fleming MF, Barry KL, Macdonald R. The Alcohol Use Disorders Identification Test (AUDIT) in a college sample. Subst Use Misuse 1991; 26(11): 1173-85. doi:10.3109/ 10826089109062153

25. National Health and Medical Research Council. Australian guidelines to reduce health risks from drinking alcohol. Canberra: Australian Government; 2009.
26. Babor TF, Higgins-Biddle JC, Saunders JB, Monteiro MG. The Alcohol Use Disorders Identification Test: guidelines for use in primary care. Geneva: World Health Organization; 2001.

27. Australian Bureau of Statistics. National nutrition survey users' guide 1995 Catalogue No. 4801.0. Canberra: ABS; 1998.

28. Australian Bureau of Statistics. National health survey 2007-2008: summary of results. Cat no 4364.0. Canberra: 2009.

29. Australian Government Department of Health and Ageing. Dietary guidelines for Australians: a guide to healthy eating. 2005. Available from: http://www.nhmrc.gov. au/_files_nhmrc/file/publications/synopses/n31.pdf [Verified 4 May 2011]

30. Australian Institute of Health and Welfare. The active Australia survey: a guide and manual for implementation, analysis and reporting. Canberra: AlHW; 2003.

31. Department of Health and Aged Care. An active way to better health. National physical activity guidelines for adults. 1999.

32. Dobbinson S, Jamsen K, Francis K, Dunlop S, Wakefield M. 2006-07 National Sun Protection Survey: Report 1. Cancer Council Australia, Australian Government Department of Health and Ageing; 2007.

33. Livingston PM. White V. Hayman J, Dobbinson S. Australian adolescents' sun protection behavior: Who are we kidding? Prev Med 2007; 44: 508-12. doi:10.1016/ j.ypmed.2007.02.015

34. SAS Institute Inc. 9.2 edn. Cary, NC.

35. Prochaska JJ, Spring B, Nigg CR. Multiple health behavior change research: an introduction and overview. Prev Med 2008; 46(3): 181-8. doi:10.1016/j.ypmed. 2008.02.001

36. Peterson S, Duncan DP, Null DB, Roth SL, Gill L. Positive changes in perceptions and selections of healthful foods by college students after a short-term point-ofselection intervention at a dining hall. J Am Coll Health 2010; 58(5): 425-31. doi:10.1080/07448480903540457

37. Dick M, Lee A, Bright M, Turner $K$, Edwards R, Dawson J, et al. Evaluation of implementation of a healthy food and drink supply strategy throughout the whole school environment in Queensland state schools, Australia. Eur J Clin Nutr 2012; 66(10): 1124-9. doi:10.1038/ejcn.2012.108

38. Dobbins M, De Corby K, Robeson P, Husson H, Tirilis D. School-based physical activity programs for promoting physical activity and fitness in children and adolescents aged 6-18. Cochrane Database Syst Rev 2009; 1: CD007651.

39. Eagle TF, Gurm R, Smith CA, Corriveau N, Durussell-Weston J, Palma-Davis L, et al. A middle school intervention to improve health behaviors and reduce cardiac risk factors. Am J Med 2013; 126(10): 903-8. doi:10.1016/j.amjmed.2013.04.019

40. Williams CL, Eng A, Botvin GJ, Hill P, Wynder EL. Validation of students' self-reported cigarette smoking status with plasma cotinine levels. Am J Public Health 1979;69(12): 1272-4. doi:10.2105/A.JPH.69.12.1272 